\title{
USING HAIR GROWTH ACTIVITY, PHYSICAL STABILITY, AND SAFETY TESTS TO STUDY HAIR TONICS CONTAINING ETHANOL EXTRACT OF LICORICE (GLYCYRRHIZA GLABRA LINN.)
}

\author{
SHEILA MEITANIA UTAMI, JOSHITA DJAJADISASTRA, FADLINA CHANY SAPUTRI* \\ Department of Herbal, Faculty of Pharmacy, Universitas Indonesia, Depok, Indonesia. Email: fadlina.chany@farmasi.ui.ac.id
}

Received: 21 April 2017, Revised and Accepted: 18 August 2017

ABSTRACT

Objective: The purpose of this study was to determine the safety, physical stability, and hair growth activity of ethanol extract of licorice.

Methods: In this study, 2.5\%, 5\%, and 10\% licorice extract was formulated into a hair tonic as a tonic is easier to use and is not sticky like a semisolid dosage. The hair growth activity test was conducted by rubbing the hair tonic preparations on rabbit's backs; subsequently, the hair length, hair thickness, hair weight, and hair density were measured. Quantitative analysis of glycyrrhizic acid from the licorice ethanol extract with a ultraviolet spectrophotometer showed a level of about $156.65 \mathrm{mg} / \mathrm{g}$ or $15.665 \%$. The physical stability test was performed on samples of the tonic stored at low $\left(4 \pm 2^{\circ} \mathrm{C}\right)$, room $\left(25 \pm 2^{\circ} \mathrm{C}\right)$, and high $\left(40 \pm 2^{\circ} \mathrm{C}\right)$ temperature, and a cycling test was also performed. The safety test was performed using an eye irritation test that employed the Hen's egg test-chorioallantoic membrane (HET-CAM) method and a skin irritation test that employed the patch test method.

Results: The hair tonics containing 5\% and 10\% licorice extract had an equivalent activity of hair growth and even better than the positive control containing $2 \%$ minoxidil. The physical stability test showed that the licorice extract hair tonic has good physical stability. The results of the safety test showed no skin irritation, whereas the HET-CAM test showed that the hair tonic containing licorice extract showed mild eye irritation.

Conclusions: Licorice ethanol extract hair tonic solutions in concentrations of $2.5 \%$, $5 \%$, and $10 \%$ had hair growth activity similar to that of the positive control (minoxidil). They have a good physical and chemical stability, also safe for topical use, except the $2.5 \%$ licorice ethanol extract hair tonic solution which caused mild eye irritation.

Keywords: Licorice, Hair growth activity, Glycyrrhizic acid, Mild irritation.

(C) 2017 The Authors. Publishedby Innovare Academic Sciences PvtLtd. This is an open access article under the CC BY license (http://creativecommons. org/licenses/by/4. 0/) DOI: http://dx.doi.org/10.22159/ijap.2017.v9s1.20_25

\section{INTRODUCTION}

Hair protects against environmental factors, such as harsh temperatures and ultraviolet (UV) light. Similar to how eyelashes protect the eye from dust and nose hair protects the nose by filtering inhaled hair, hair also protects the scalp against irritants. Hair also has a role in perspiration and temperature regulation and has sensitive tactile senses [1]. Hair has a growth and loss cycle that differs between each strand [2]. Although hair loss is part of the natural hair cycle, an increase in the quantity and frequency of hair loss results in balding. This increased quantity and frequency of hair loss usually stem from stress, food consumption, hormonal disturbances, and the side effects of medications.

The use of shampoo and conditioner is usually not enough as a hair treatment to counter hair loss because hair is a vital cell that needs high care and maintenance to stay healthy. Therefore, hair tonics can be used for hair treatment [3]. Hair tonics are used to thicken hair or to stimulate hair growth in people experiencing balding or hair loss [4]. In general, hair tonics contain irritants, such as alcohol, camphor, capsicum, cantharidin, cinnamon, garlic, vitamin, ginseng, or nicotinic acid [3]. Currently, most Indonesians choose to use herbal products due to their minimal side effects compared with synthetic products, such as minoxidil, which has side effects such as scalp sensitivity [5].

Licorice has been used in Ayurveda and Chinese medicine for its antihair loss effect and its ability to restore dry hair. Its main components, glyceric acid and its derivatives, are suspected to produce an anti-hair loss effect by inhibiting the production of dihydrotestosterone (DHT) through the suppression of 5-alpha-reductase enzyme activity, which subsequently increases hair growth [6-8]. A study by Khalaf et al. (2010) on methanol extract from licorice showed that there were eight components with phytoestrogen activity (seven isoflavone components and one coumestan component): Daidzein, daidzin, genistein, glycitein, formononetin, ononin, and coumestrol. The phytoestrogen components contained in licorice (isoflavone, daidzin, genistein, and glycitein) act as active components in hair loss prevention by blocking the production of DHT (a DHT blocker) and a $\beta$-sitosterol compound, which is a hair regrowth promoter [9]. Glabridin and glabrene are flavonoids contained in licorice that is suspected to have estrogen-like activity. One study proved that petroleum ether extracted from licorice roots had the potential to act as an agent to promote hair growth in female white rats (Rattus norvegicus) [10].

The glyceric acid compound and its derivatives and phytoestrogen in licorice have been suspected to promote hair growth. However, a study on the activity of the compounds derived from licorice on hair growth has not been conducted. This study was expected to produce raw materials for a hair growth product with minimum side effects. The study involved experimentation and observation of the hair growth of New Zealand rabbits. This study also uses a stability and safety test using the patch test and Hen's egg test-chorioallantoic membrane (HET-CAM).

\section{MATERIALS AND METHODS}

\section{Materials}

This study used the following materials: Licorice extract (PT Tri Rahardja Javaplant, Karanganyar, Indonesia), 2\% minoxidil $\left(\right.$ Regrou $^{\circledR}$, obtained from PT Surya Dermato Medica Laboratories, Surabaya, Indonesia), 96\% ethanol (PT Brataco, Jakarta, Indonesia), distilled water, propylene glycol (PEG) (PT Brataco, Jakarta, Indonesia), Microcare ${ }^{\circledR}$, PEG-40 hydrogenated castor oil and water, BHT (PT Brataco, Jakarta, Indonesia), $2 \mathrm{~N}$ hydrochloride acid $(\mathrm{HCl})$, Veet ${ }^{\circledR}$ cream (PT Reckitt Benckiser, Bogor, Indonesia), Lieberman-Burchard reagent, Mayer reagent, Dragendorf reagent, 50\% methanol, magnesium (Mg), dense $\mathrm{HCl}$, Chloroform $\left(\mathrm{CHCl}_{3}\right)$, sulfuric acid $\left(\mathrm{H}_{2} \mathrm{SO}_{4}\right)$ p.a., sodium hydroxide $(\mathrm{NaOH})$, acetate anhydride acid, Iron(III) chloride $\left(\mathrm{FeCl}_{3}\right)$ solution, $0.4 \mathrm{M}$ lead (II) acetate, isopropanol, anhydrous sodium sulfate, molish LP, and standard glyceric acid (Sigma Aldrich, Nucleos, Singapore). 
Production of licorice ethanol extract

First, $5 \mathrm{~L}$ of ethanol was added to $500 \mathrm{~g}$ of dry licorice extract powder and macerated at room temperature for approximately $48 \mathrm{hrs}$. Then, after the filtrate and residue were separated, the filtrate was condensed using a rotary evaporator at $60^{\circ} \mathrm{C}$ or lower and was macerated again for $12 \mathrm{hrs}$ by adding $3 \mathrm{~L}$ of ethanol and filtering it. This procedure was repeated thrice to obtain a combination filtrate. Next, $1 \mathrm{~L}$ of $70 \%$ ethanol was added and was maintained at a cool temperature for at least $48 \mathrm{hrs}$. The residue and filtrate were separated through filtration. The obtained filtrate was condensed to produce licorice ethanol extract. This procedure was expected to attract $3-4 \%$ or more glyceric acid as its main active component [11].

\section{Determination of the glyceric acid concentration}

A standard solution was produced by dissolving $10 \mathrm{mg}$ of standard glyceric acid in $100 \mathrm{~mL}$ of distilled water to obtain a master solution of $100 \mathrm{ppm}$. The master solution was diluted into solutions of differing concentrations, and the maximum wavelength and absorption scores of the solutions were calculated using a UV spectrophotometer. A calibration curve was made from the absorption scores.

A licorice extract sample solution was produced by dissolving $1 \mathrm{~g}$ of the licorice extract sample in $100 \mathrm{~mL}$ of distilled water to obtain a master solution of $1000 \mathrm{ppm}$. The solution was then diluted, and the absorption scores were calculated using a UV spectrophotometer with the maximum wavelength that had been previously determined based on the calculations of the glyceric acid standard solution. The obtained absorption scores were added to a formula on the calibration curve to obtain the concentration of glyceric acid contained in the licorice extract sample.

\section{Production of the hair tonic}

The formula was divided into three groups of differing licorice extract concentrations: $2.5 \%, 5 \%$, and $10 \%$. The materials were weighed according to the formula. In the oil phase, 1.2\% PEG-40 hydrogenated castor oil was mixed with a little ethanol. In another container, $0.5 \%$ BHT, $0.1 \%$ menthol, and $0.5 \%$ microcare were dissolved with ethanol, PEG was added little by little, and the solution stirred until it was thoroughly mixed. The oil phase, the licorice extract solution, and the water phase were mixed thoroughly, and the volume of the mixed solution was increased by adding distilled water.

\section{Evaluation of the hair tonic}

\section{Organoleptic examination}

A visual examination of the odor, shape, and color of the produced hair tonic was conducted.

\section{Viscosity test}

To test the hair tonic's viscosity, $250 \mathrm{ml}$ of the tonic was poured into a Becker glass, and a spindle 1 was inserted to a previously determined limit. Measurements were conducted with a Brookfield viscometer at speeds of 5, 10,20,50, and $100 \mathrm{rpm}$. The obtained data were plotted to sliding pressure $\left(\right.$ dyne $\left./ \mathrm{cm}^{2}\right)$ and sliding speed.

\section{pH measurement}

The measurement of the $\mathrm{pH}$ of the solutions was conducted using a $\mathrm{pH}$ meter, and the $\mathrm{pH}$ was measured once every 1 weeks for 12 weeks.

\section{Testing the physical stability of the hair tonic}

The physical stability of the hair tonic tested in this study included its odor, color, homogeneity, $\mathrm{pH}$, and viscosity. The hair tonic's physical stability was evaluated at room $\left(25 \pm 2^{\circ} \mathrm{C}\right)$, warm $\left(40 \pm 2^{\circ} \mathrm{C}\right)$, and cold $\left(4 \pm 2^{\circ} \mathrm{C}\right)$ temperatures every 2 weeks for 12 weeks. A cycling test was also conducted (six cycles) [12].

\section{Hair growth activity test}

This study used male New Zealand rabbits from Balai Penelitian Hewan Ternak, Ciawi, that weighed 2-2.5 kg. Tanaka et al. modification was used to measure hair growth [13]. The hairs on the rabbits' backs were divided into $5 \times 10 \mathrm{~cm}$ test areas. After the rabbits' backs were shaved, six squares were made: Three squares on the left side and three squares on the right side of the rabbits' backs with measurements of $2.2 \mathrm{~cm} \times 2.5$ each. Every test area was marked with a marker. Each test involved the application of a different treatment. The rabbits were left for $24 \mathrm{hrs}$ before the experiment. $1 \mathrm{~mL}$ of each sample was applied twice a day for 6 weeks. The first day of the application was considered day 0 . Hair growth was measured based on hair length, density, weight, and thickness.

\section{Safety test}

The safety test was conducted using the HET-CAM as an alternative to the mucous membrane safety test method (for eye irritation) to avoid the use of animals. The safety test was conducted by 20 volunteers who were 17-30 years old [14]. The volunteers were chosen by inclusion and exclusion criteria for participation in the study.

\section{RESULTS}

Determination of the concentration of glyceric acid in licorice ethanol extract

The determination of glyceric acid in licorice ethanol extract was done using a Hitachi U-2910 UV spectrophotometer with glyceric acid from Sigma-Aldrich as a standard. Distilled water was used as a solvent because of its dissolving properties and its ready availability [15].

The standard glyceric acid solution was diluted into concentrations of $10 \mathrm{ppm}, 20 \mathrm{ppm}, 30 \mathrm{ppm}, 40 \mathrm{ppm}$, and $50 \mathrm{ppm}$. The maximum wavelength measurement, which was $256.5 \mathrm{~nm}$, was then obtained with the UV spectrophotometer, and the absorption scores of each concentration were determined to be $0.140,0.289,0.433,0.606$, and 0.729 , respectively. The obtained absorption scores were plotted with the concentration to obtain a calibration curve formula.

The licorice extracts weighed $1 \mathrm{~g}$, and the sample concentration of the standard was $313.3 \mu \mathrm{g} / \mathrm{ml}$. Finally, the glyceric acid concentration in the licorice extract, $156.65 \mathrm{mg} / \mathrm{g}$ or $15.665 \%$, was obtained.

\section{Hair growth activity test}

\section{Hair length parameter}

Hair length was measured every week from the $1^{\text {st }}$ week of application to the $6^{\text {th }}$ week. The measurement was done by randomly taking 10 strands of hair from each test area and measuring their length using a digital caliper. The mean hair length of each week's samples is shown in Table 1.

The results of the normality distribution test (Shapiro-Wilk test) and the homogeneity test (Levene test) on the mean length of the hair in each test group each week showed that the distribution of data was normal and homogeneous every week ( 6 weeks in total). Therefore, analysis of variance (ANOVA) testing was performed. The results of the ANOVA test showed that there was no significant difference between the test groups in weeks 4,5 , and 6 . To find whether there was a significant difference between the test groups, a least significant difference (LSD) test was conducted. In week 2 , the normality distribution test showed that the data were normally distributed. However, the homogeneity test showed that the data were not homogenous, so a non-parametric data analysis was conducted using the Kruskal-Wallis test.

\section{Hair weight parameter}

Hair weight was measured on the $42^{\text {nd }}$ day (the end of week 6 ) by pulling all the hair from a $1 \times 1-\mathrm{cm}$ area in each test area and weighing the hair. The weights of the samples are shown in Table 2.

The mean weights of the normal control, negative control, positive control, formula 1 , formula 2 , and formula 3 groups were $93.7 \pm 8.88 \mathrm{mg}$, $97.26 \pm 6.15 \mathrm{mg}, 115.3 \pm 15.00 \mathrm{mg}, 114.56 \pm 7.34 \mathrm{mg}, 130.66 \pm 11.38 \mathrm{mg}$, and $118.52 \pm 8.50 \mathrm{mg}$, respectively. Statistical analysis was needed to assess whether there was a difference between the weights of 
Table 1: The mean length of rabbit hair each week

\begin{tabular}{|c|c|c|c|c|c|c|c|}
\hline \multirow[t]{2}{*}{ Test group } & \multirow[t]{2}{*}{ Treatment } & \multicolumn{6}{|c|}{ Mean hair length $(\mathrm{mm}) \pm \mathrm{SD}$} \\
\hline & & M1 & M2 & M3 & M4 & M5 & M6 \\
\hline Group 1 & Normal control & $5.13 \pm 1.42$ & $5.79 \pm 2.26$ & $10.18 \pm 3.26$ & $13.70 \pm 1.86$ & $16.26 \pm 1.92$ & $16.37 \pm 5.69$ \\
\hline Group 2 & Negative control & $7.82 \pm 4.07$ & $9.25 \pm 6.56$ & $12.98 \pm 5.71$ & $17.23 \pm 5.61$ & $19.45 \pm 3.49$ & $19.87 \pm 7.92$ \\
\hline Group 3 & Positive control ( $2 \%$ minoxidil) & $9.23 \pm 3.84$ & $10.18 \pm 7.27$ & $13.57 \pm 6.06$ & $19.22 \pm 5.20^{*, * *}$ & $21.45 \pm 4.81^{*, * *}$ & $22.80 \pm 6.46$ \\
\hline Group 4 & Formula 1 (2.5\% licorice) & $5.81 \pm 4.51$ & $7.45 \pm 3.73$ & $11.64 \pm 4.17$ & $15.27 \pm 0.93$ & $20.40 \pm 5.01$ & $16.24 \pm 4.50$ \\
\hline Group 5 & Formula 2 (5\% licorice) & $6.78 \pm 4.28$ & $8.86 \pm 4.73$ & $12.80 \pm 5.35$ & $18.57 \pm 2.98$ & $21.70 \pm 5.31$ & $22.78 \pm 5.66$ \\
\hline Group 6 & Formula 3 (10\% licorice) & $8.85 \pm 5.27$ & $11.30 \pm 8.63$ & $16.67 \pm 6.90$ & $21.66 \pm 5.02^{*}$ & $24.45 \pm 4.86^{*}$ & $29.18 \pm 8.97^{*, * *}$ \\
\hline
\end{tabular}

SD: Standard deviation. ${ }^{*}$ Significantly different $(\mathrm{p}<0.05)$ from the normal control, ${ }^{* *}$ significantly different $(\mathrm{p}<0.05)$ from the negative control

hair. Based on a normality distribution test (Shapiro-Wilk test) and a homogeneity test (Levene test) of the mean weights of the hair, the data distribution was normal and homogeneous. The results of the LSD test showed that the normal and negative controls did not show a significant difference, meaning that the activity of the negative control on the weight of the hair was similar to that of the normal control. The three formulas showed a significant difference when they were compared with the negative control. However, formulas 1 and 3 were not significantly different from the positive control, whereas formula 2 differed significantly from the positive control.

\section{Hair density parameter}

Hair density was measured by counting the amount of hair per $\mathrm{cm}^{2}$ area on the $42^{\text {nd }}$ day (the end of week 6). The results are shown in Table 3.

The mean amounts of hair of the normal control, negative control, positive control, formulas 1-3 groups were $1202 \pm 49,1300 \pm 102$, 1502 \pm 82 , $1457 \pm 263,1621 \pm 286$ and $1322 \pm 146$, respectively. Statistical analysis was needed to assess whether there was a difference between the hair densities. The normality distribution test (Shapiro-Wilk Test) and the homogeneity test (Levene Test) on the mean amounts of hair showed that the data distribution was normal and homogeneous. The LSD test showed that the normal control and negative control did not have a significant difference, meaning that the normal control and negative control resulted in similar hair densities. When the positive control was compared with the results of formulas 1-3, the three formulas did not differ significantly from the positive control. This result shows that formulas 1-3 showed hair densities similar to that of the positive control. However, formula 2 differed significantly from formula 3.

\section{Parameter of hair thickness}

Hair thickness was assessed by measuring the thickness of hair strands (diameter) at week 1 and week 6 using a scanning electron microscope. The results are shown in Table 4. The diameters of the hair strands of the normal control, negative control, positive control, formulas 1-3 groups in week 1 were $11.00 \pm 0.96 \mu \mathrm{m}, 16.75 \pm 0.73 \mu \mathrm{m}, 64.63 \pm 1.57 \mu \mathrm{m}$, $67.32 \pm 4.64 \mu \mathrm{m}, 31.80 \pm 3.14 \mu \mathrm{m}$, and $71.72 \pm 3.39 \mu \mathrm{m}$, respectively. The diameters of the hair strands in week 6 were $47.83 \pm 9.22 \mu \mathrm{m}$, $109.72 \pm 3.87 \mu \mathrm{m}, 119.12 \pm 5.88 \mu \mathrm{m}, 90.35 \pm 5.06 \mu \mathrm{m}, 60.19 \pm 7.61 \mu \mathrm{m}$, and $112.65 \pm .24 \mu \mathrm{m}$, respectively.

\section{Evaluation of the hair tonic}

\section{Measurement of viscosity and rheology}

The viscosity of the hair tonic was measured at weeks 0 and 12 , and the solutions were stored at temperatures of $4 \pm 2^{\circ} \mathrm{C}, 25 \pm 2^{\circ} \mathrm{C}$, and $40 \pm 2^{\circ} \mathrm{C}$. The obtained data were then plotted with sliding pressure $\left(\right.$ dyne $\left./ \mathrm{cm}^{2}\right)$ and sliding speed (rpm) until a flow property (rheology) was obtained. The measurement of the viscosity at week 12 showed that there was no change in the viscosity of the hair tonic. The rheogram showed that the flow type from the hair tonic was Newton.

\section{Physical stability test of the hair tonic}

The three hair tonic formulas were stable at the low $\left(4 \pm 2^{\circ} \mathrm{C}\right)$, room $\left(25 \pm 2^{\circ} \mathrm{C}\right)$, and high $\left(40 \pm 2^{\circ} \mathrm{C}\right)$ temperatures. The cycling test of the hair tonic formulas resulted in neither a physical change nor a separation of phases.
Table 2: The mean weight of rabbit hair in week 6

\begin{tabular}{lll}
\hline $\begin{array}{l}\text { Test } \\
\text { group }\end{array}$ & Treatment & $\begin{array}{l}\text { Mean hair } \\
\text { weight }(\mathbf{m g}) \pm \text { SD }\end{array}$ \\
\hline Group 1 & Normal control & $93.7 \pm 8.88$ \\
Group 2 & Negative control & $97.26 \pm 6.15$ \\
Group 3 & Positive control & $115.3 \pm 15.00^{*, * *}$ \\
Group 4 & Formula 1 (2.5\% licorice extract) & $114.56 \pm 7.34^{* * * *}$ \\
Group 5 & Formula 2 (5\% licorice extract) & $130.66 \pm 11.38^{*, * *}$ \\
Group 6 & Formula 3 (10\% licorice extract) & $118.52 \pm 8.50^{*, * *}$ \\
\hline
\end{tabular}

SD: Standard deviation. *Significantly different $(\mathrm{p}<0.05)$ from the normal control, $* *$ significantly different $(\mathrm{p}<0.05)$ from the negative control

Table 3: The mean amount of hair at week 6

\begin{tabular}{lll}
\hline Test group & Treatment & $\begin{array}{l}\text { Mean amount } \\
\text { of hair } \pm \text { SD }\end{array}$ \\
\hline Group 1 & Normal control & $1202 \pm 49$ \\
Group 2 & Negative control & $1300 \pm 102$ \\
Group 3 & Positive control & $1502 \pm 82^{*, * *}$ \\
Group 4 & Formula 1 (2.5\% licorice extract) & $1457 \pm 263^{*, * *}$ \\
Group 5 & Formula 2 (5\% licorice extract) & $1621 \pm 286^{*, * *}$ \\
Group 6 & Formula 3 (10\% licorice extract) & $1322 \pm 146$ \\
\hline
\end{tabular}

SD: Standard deviation. *Significantly different $(\mathrm{p}<0.05)$ from the normal control, **significantly different $(\mathrm{p}<0.05)$ from the negative control

Table 4: The mean hair diameter at week 6

\begin{tabular}{|c|c|c|c|}
\hline \multirow[t]{2}{*}{$\begin{array}{l}\text { Test } \\
\text { group }\end{array}$} & \multirow[t]{2}{*}{ Treatment } & \multicolumn{2}{|c|}{$\begin{array}{l}\text { Mean hair } \\
\text { diameter }(\mu \mathrm{m}) \pm S D\end{array}$} \\
\hline & & Week 1 & Week 6 \\
\hline Group 1 & Normal control & $11.00 \pm 0.96$ & $47.83 \pm 9.22$ \\
\hline Group 2 & Negative control & $16.75 \pm 0.73$ & $109.72 \pm 3.87$ \\
\hline Group 3 & Positive control & $64.63 \pm 1.57$ & $119.12 \pm 5.88$ \\
\hline Group 4 & $\begin{array}{l}\text { Formula } 1 \text { ( } 2.5 \% \text { licorice } \\
\text { extract) }\end{array}$ & $67.32 \pm 4.64$ & $90.35 \pm 5.06$ \\
\hline Group 5 & $\begin{array}{l}\text { Formula } 2 \text { (5\% licorice } \\
\text { extract) }\end{array}$ & $31.80 \pm 3.14$ & $60.19 \pm 7.61$ \\
\hline Group 6 & $\begin{array}{l}\text { Formula } 3 \text { (10\% licorice } \\
\text { extract) }\end{array}$ & $71.72 \pm 3.39$ & $112.65 \pm 6.24$ \\
\hline
\end{tabular}

\section{Measurement of $\mathbf{p H}$}

The $\mathrm{pH}$ of the three hair tonic formulas was stable at around 5.6-5.9.

\section{Safety test}

\section{HET chloriallantoic}

The HET-CAM can observe hemorrhaging, lysis, and coagulation. Hemorrhaging is defined as bleeding or blood leaving the circulatory system. Lysis is the absence or the disappearance of small, fine arteries after a hemorrhage. Coagulation, which can happen intra- or extra-cellular, is the clotting of blood, which can appear a dark stain and which may happen as a reaction of opacifying or turbidity of the CAM. 
The results of the HET-CAM showed that, during the 5 minutes of observation time, a lysis and coagulation reaction did not occur for the three test groups. According to the irritation score obtained, the negative control was non-irritative, whereas the positive control and the $2.5 \%$ licorice ethanol extract were irritative. The irritative properties contained in the hair tonic solution stemmed from the properties of PEG and menthol, which might be slightly irritative to the eye.

\section{Patch test}

The safety test for skin irritation was conducted with a single closed patch test for $48 \mathrm{hrs}$ and was attended by 20 volunteers who filled the inclusion criteria. The solutions used for the irritation safety test were a basic hair tonic and a $2.5 \%$ licorice ethanol extract hair tonic solution. Before treatment, the volunteers signed an informed consent form. A dose of $0.1 \mathrm{~mL}$ of the two solutions of hair tonic was applied to the upper back of each volunteer, which was observed after 30 minutes, $24 \mathrm{hrs}$, and $48 \mathrm{hrs}$ to assess whether there were any erythema or edema reactions.

The results of the primary irritation index (PII) scoring for the basic hair tonic and $10 \%$ licorice ethanol extract showed that the PII was 0.125 , so the irritation was classified as insignificant (0-0.4). Based on the results, the basic hair tonic and the $10 \%$ licorice ethanol extract were safe for topical use.

\section{DISCUSSION}

Based on the hair growth activity test, formula 1 (2.5\% licorice ethanol extract), formula 2 (5\% licorice ethanol extract), and formula 3 (10\% licorice ethanol extract) had hair growth activity as compared to the activity of positive control, minoxidil. However, formulas 2 and 3 showed significantly better hair growth activity than that of the positive control. For hair weight, formulas 1 and 3 had results similar to that of the positive control. However, formula 2 (5\% licorice ethanol extract) had better results than the positive control.

Based on the mean amount of hair, formula 2 had the best results of the three formulas. The bigger and rougher texture of the hair strands seen in subjects to which formulas 1 and 3 were applied might cause the amount of hair per $\mathrm{cm}^{2}$ to be less than that seen in formula 2. The hair density parameter has shown that the positive control and the three formulas stimulate hair follicles through the growth of new hair. Based on the graphic seen in attachment 49 and Table 4, an increase in the diameter (thickness) of each hair strand between week 1 and week 6 was evident. The difference in hair diameter between the test groups was also evident. The positive control group had the largest hair strands according to diameter, followed by the formula 3, formula 1, negative control, and normal control groups. Based on the four hair growth parameters, the three licorice ethanol extract hair tonic formulas had activities similar to the positive control. However, formulas 2 and 3 had significantly better hair growth activity than the positive control.

The mechanism of action or chemical compound responsible for the hair growth activity of licorice ethanol extract might be glyceric acid and its derivatives and glycyrrhizic acid and its derivatives, which are suspected to have anti-hair loss effects resulting from the inhibition of the production of DHT through suppression of 5-alpha-reductase activity $[8,16,17]$. According to phytochemistry identification, licorice ethanol extract contains flavonoid and terpenoid, which can increase hair growth by strengthening the capillary walls of the small blood vessels that supply the hair follicles and by increasing blood flow to hair follicles [18]. Alkaloids can enlarge hair strands, increasing the food supply and nutrition to hair [19]. Saponin is a chemical compound mostly found in licorice extracts that can stimulate hair growth in alopecia (balding) cases caused by hormones or genetics. Saponin can form bubbles, meaning it can clean dirt from the skin and can also act as a counterirritant. Saponin can increase peripheral blood circulation, thereby increasing hair growth [20]. Moreover, the phytoestrogen compounds (isoflavone daidzin, genistein, and glycitein) contained in licorice are the active ingredients in preventing hair loss by blocking the formation of DHT (a DHT blocker), and the $\beta$-sitosterol compound acts as a hair regrowth promoter [9].

Based on the results obtained from this research, the licorice extract hair tonic accelerated the active phase of hair growth, prolonged the active phase, and stimulated hair follicles, leading to larger strands of rabbit hair. Based on the stability test, which studied the solutions' color, odor, and $\mathrm{pH}$ stability, the hair tonic solutions showed good physical stability when stored at low $\left(4 \pm 2^{\circ} \mathrm{C}\right)$, room $\left(25 \pm 2^{\circ} \mathrm{C}\right)$, and high $\left(40 \pm 2^{\circ} \mathrm{C}\right)$ temperatures. The safety test, which examined the skin irritation of the hair tonic solutions containing 10\% licorice ethanol extract on 20 volunteers, showed that the solutions were safe for skin. However, the eye irritation test showed that the $2.5 \%$ licorice ethanol extract hair tonic solutions were irritative to the eyes.

\section{CONCLUSION}

Licorice ethanol extract hair tonic solutions in concentrations of $2.5 \%, 5 \%$, and $10 \%$ had hair growth activity similar to that of the positive control (minoxidil) according to the hair length and hair thickness parameters. The $5 \%$ and $10 \%$ licorice ethanol extract hair tonic solutions had better hair weight and density than that of the positive control. However, the $5 \%$ hair tonic solution had worse hair density results than the positive control. The concentration of glycyrrhizic acid contained in the licorice ethanol extract used as an active ingredient in the hair tonic solutions was $1456.65 \mathrm{mg} / \mathrm{g}$ or $5.665 \%$. The hair tonic solutions containing $2.5 \%, 5 \%$, and $10 \%$ licorice ethanol extract showed physical and chemical stability when stored at low $\left(4 \pm 2{ }^{\circ} \mathrm{C}\right)$, room $\left(28 \pm 2^{\circ} \mathrm{C}\right)$, and high $\left(40 \pm 2^{\circ} \mathrm{C}\right)$ temperatures for 12 weeks. The HET-CAM and patch safety test showed that the $10 \%$ licorice ethanol extract hair tonic solution was safe for topical use. However, the $2.5 \%$ licorice ethanol extract hair tonic solution was irritative to the eye.

\section{REFERENCES}

1. Harahap M. Ilmu Penyakit Kulit. $1^{\text {st }}$ ed. Jakarta: Hipokrates; 2000

2. Mitsui T. New Cosmetic Science. Amsterdam: Elsevier Science B.V. Nakayama Shoten Publishers; 1992.

3. Wasiaatmadja SM. Penuntun Ilmu Kosmetik Medik. $1^{\text {st }}$ ed. Jakarta: Universitas Indonesia Press; 1997.

4. Indonesian Ministry of Health. Formularium Kosmetika Indonesia. Jakarta: Indonesian Ministry of Health; 1985.

5. Purwal L, Gupta S, Pande M. Development and evaluation of herbal formulations for hair growth. EJ Chem 2008;5(1):34-8

6. Ha KB, Bae W, Kim SN, Kim AR, Jung KM, Kim EJ, et al. Cosmetic Composition for Inhibiting Hair Loss and Enhanched Hair Growth. United States Patent Application Publication. US 2013/0089632 A1; 2013.

7. Nam JH. Hair Growth Stimulants and the Manufacturing Method Thereof. United States Patent. US 8,298,592 B2; 2012.

8. Aimi M, Nemori R, Ogiwara K. Casien Nanoparticle. US2009-0280148 A1; 2009 .

9. Lourith N, Kanlayavattanakul M. Hair loss and herbs for treatment. J Cosmet Dermatol 2013;12(3):210-22.

10. Upadhyay S, Ghosh AK, Singh V. Hair growth promotant activity of petroleum ether root extract of Glycyrrhiza glabra L (Fabaceae) in female rats. Trop J Pharm 2012;11(5):753-8.

11. Yakuji Nippo Ltd. Official Monoghraphs for Part II. Japanese Pharmacopoeia. $14^{\text {th }}$ ed. Tokyo: Yakuji Nippo Ltd.; 2008. p. 933-4.

12. Djajadisastra J. Cosmetic Stability. Seminar Setengah Hari HIKI Depok: Departemen Farmasi Fakultas Matematika dan Ilmu Pengetahuan Alam Universitas Indonesia ; 2004.

13. Tanaka S, Saito M, Tabasa M. Bioassay of crude drug for hair growth promoting activity in mice by a new simple methods. Plant Med Suppl 1980;40:84-90.

14. Schrader K, Domsch A. Cosmetology-Theory and Practice. $1^{\text {st }}$ ed. Jerman: Verlag Fur Chemische Industrie; 2005.

15. Raja MS, Khan I, Perumal P, Srikakolapu SR, Gotteti SD. Quantitative analysis of glycyrrhizic acid in crude drug and its herbal. Arch Appl Sci Res 2010;3(3):703-6.

16. Kang JI, Kim EJ, Kim MK, Jeon YJ, Kang SM, Koh YS, et al. The 
promoting effect of Ishige sinicola on hair growth. Mar Drugs 2013;11(6):1783-99.

17. Nam YJ, Tran LS, Kojima M, Sakakibara H, Nishiyama R, Shin R. Regulatory roles of cytokinins and cytokinin signaling in response to potassium deficiency in Arabidopsis. PLoS One 2012;7(10):e47797.

18. Allayie SA, Hemalatha S, Elanohezhiyan C, Manoharan V, Balasubramanian $\mathrm{K}$, Sheikh BA. In vivo evaluation of hair growth potential of fresh leaf extracts of Naringi crenulata. J Clin Exp
Dermatol Res 2012;3(2):1-4.

19. Sigit H. Pengaruh Ekstrak Etanol Daun Mangkokan (Nothopanx scutellarium L.) Terhadap Kecepatan Pertumbuhan Rambut Kelinci Jantan dan Profil Kromatogram lapis Tipisnya. Thesis. Surakarta: Universitas Muhammadiyah Surakarta; 2005.

20. Sadiah S, Herlina N, Indriati D. Effectivity of Ethanol $70 \%$ Extract of Mangkokan (Nothopanax scutellarius (Burm. f) Merr) Leaves in Emulsion Form as Hair Growth Stimulant. Fitofarmaka 2014;4(1):10-7. 